To clarify his fourth point, the final course of chloroquine with doxycycline was given by the parents at home, as the child was clinically well and they insisted on her discharge on 21 July. Hence we are unable to comment on blood slides taken between 25 July and 24 August. The 24 August slide was taken when the child came for an outpatient appointment.

Finally, I would reiterate the main point of our report, which was that the child was given a very adequate course of chloroquine between 25 June and 7 July. Chloroquine absorption is proved by the positive Haskin's test. Despite this, the blood test was positive on 12 July and 19 July. This demonstrates that her malarial infection was resistant to a generous course of chloroquine, more than the generally recommended dosage. I would also like to take this opportunity of correcting the last line of our penultimate paragraph. It should read "this is a generous dosage," not "the general dosage" by WHO standards.

Professor Khan and I would like to apologise for the confusion resulting from the inaccurate figure but hope that as a result of the report workers in Africa will watch more closely for chloroquine resistance, as this will obviously pose many new problems.

M J Maguire

Northampton

\section{Whole gut irrigation}

SIR,-We would like to sound a word of caution regarding the treatment of faecal stasis and constipation with whole gut irrigation as suggested by Dr R G Smith and others (5 August, p 396). A 66-year-old patient was recently admitted to this hospital with long history of constipation alternating with spurious diarrhoea. She had had a bariumenema examination two years previously which had shown diverticular disease. Initially she was treated with enemas with little success. Whole gut irrigation was then attempted as described in the article by Dr Smith and his colleagues. Her abdominal distension increased over the next $24 \mathrm{~h}$ and plain abdominal $x$-rays showed complete large-bowel obstruction where previously they had shown gross faeca loading. Laparotomy was performed which showed gross large-bowel distension with the transverse colon stuck to a diverticular mass. The bowel was so inflamed and stuck that resection was not possible. Large drains were left in the abdomen and a transverse colostomy performed. Twelve hours later she developed a Gram-negative septicaemia and died. Postmortem examination revealed an ischaemic colon which had perforated secondary to the obstruction.

We would suggest that only conventional methods of bowel clearance should be used initially and that whole gut irrigation should be confined to recurrence of faecal stasis after barium examination has excluded underlying disease.

K D VellacotT $T$ W BALFOUR

City Hospital Nottingham

SIR,-May I sound a note of caution over this technique reported by $\operatorname{Dr} R \mathrm{G}$ Smith and his colleagues (5 August, p 396)? I have reported a case ${ }^{1}$ in which a patient was found to have a base deficit totalling $350 \mathrm{mmol}$ following whole gut irrigation as a preparation for rectal surgery. There were no other detectable abnormalities either clinically or biochemically, and no cause for her acidosis, which at its maximum gave a $\mathrm{pH}$ of $7 \cdot 19$, other than the irrigation could be discovered.

It seems from reported series that a weight gain of $1 \mathrm{~kg}$ is typical and I presume represents the absorption of isotonic saline. This will promote the renal excretion of bicarbonate, which, together with losses caused by the "forced diarrhoea," is sufficient to account for the acidosis. I am not in a position to conduct a prospective trial, but may I enter a plea for at least a proportion of patients having whole gut irrigation to have an estimation of their acid/base state performed?

Selly Oak Hospital,

JOHN HURDLEY

Birmingham

${ }^{1}$ Hurdley, J, Anaesthesia, 1978, 33, 478.

\section{If I had . . . a sigmoidoscopy}

SIR,-If Dr N H Dyer's (5 August, p 418) next sigmoidoscopy is carried out in the kneechest (even more undignified than the kneeelbow) position he will be surprised to find how much easier it is for him than the left lateral position. In my experience this was the invariable reaction of patients of both sexes who had previously been examined in the more modest position, which I employed only for those who were physically incapable of adopting or maintaining the kneeling posture.

No preparation is required apart from defecation before the examination, and air insufflation, which, as Dr Dyer says, is most uncomfortable, is never necessary. For the operator the knee-chest position is far more straightforward. It affords a better view of the bowel, there is no danger of damage to the wall, and biopsy specimens are easily taken. Small lesions are more readily located at follow-up examinations and recorded pictorially. The alarming gushes of liquid faeces through the instrument, which can occur when the patient is straining in the very awkward lateral position, are impossible, and, finally, "sigmoidoscopist's headache" is avoided.

Pulborough, Sussex

W H HARGREAVES

\section{Psychiatric ward rounds}

SIR,-It is instructive how often things bad can be transformed into things good. About a year ago the charge nurses and ward sisters at this hospital undertook industrial action and refused, for a couple of weeks, to accompany patients into the clinicians' office for the purpose of the psychiatric conference as it was then undertaken. Consequently, since it was still necessary to determine the present mental state and decide future management and treatment of patients, I had to conduct the admission ward review in public in the day room. We all sat in a circle, staff and patient intermingled, and, addressing each patient in turn, I conducted almost the same kind of interview that I had been used to doing previously behind closed doors. At the end of those weeks I asked everybody what they thought of that way of doing things and with only one exception all the patients said that they preferred it.
I think that this may be largely because if a patient feels anxious and paranoid he may think that when other patients go off and see the team in private plots are being hatched against him. With everything out in the open he can see exactly what transpires, which must diminish such anxieties. There is an additional bonus which cannot be discounted. When patients who have never had experience of a group start communicating across the room, not only to the clinician but to nursing staff and fellow patients, they begin to find out that other people have the same symptoms, which gives relief. The clinician thus may take the opportunity of undertaking education in psychodynamics and the total result is that patients are better able to understand themselves and their own attitudes and behaviour.

But perhaps the biggest advantage is that in effect all the patients on the ward become members of the therapeutic team, able to offer their opinion and advice on whether one of their colleagues, for example, is now fit enough for weekend leave or for discharge. This sharing of care and management with the professionals reduces the sense of alienation which mental illness brings. Also, the need to exercise judgment in making suggestions for the treatment or management of themselves and their colleagues not only promotes all patients' alignment with the clinical team but must lead to a greater maturity in handling themselves in their relationships.

Since then I have always conducted my admission ward reviews in this way, to the great satisfaction of most. The few patients who instead or additionally wish to have a private interview are seen after the main meeting.

H Dale BecketT

Cane Hill Hospital,

Coulsdon,
Surrey

\section{Breathing other people's smoke}

SIR,-I was in joyful rapport with the views and tone of your leading article "Breathing other people's smoke” (12 August, p 453). It is an outrage, and symptomatic of a decadent society, that we have to tolerate the filthy menace of cigarette smoke in streets, offices, restaurants, cinemas, theatres, and other public places. It has been said, with the utmost seriousness, that smoking should be legal only between consenting adults in private. While there is doubt that this Utopian day will ever dawn, the BMF's powerful and authoritative campaigning on behalf of the unwilling passive smoker is greatly to be welcomed.

I am anxious, however, to draw attention to a mostly entirely unnecessary source of smoke that is generally overlooked as a health hazard, a nuisance, and a source of pollution. I refer, of course, to the garden bonfire.

You are rightly concerned that one cigarette may release $100 \mathrm{ng}$ of benzpyrene into the atmosphere. Some time ago it was estimated that about 100000 tons of tobacco are burnt each year in this country. ${ }^{1}$ The equivalent figure for garden and other rubbish was, however, estimated to be 300000 tons; and bonfire smoke contains 70 parts of benzpyrene per million of free carbon compared with only 0.2 in cigarette smoke. ${ }^{1}$ In addition, the bonfire liberates other polycyclic aromatic hydrocarbons into the atmosphere, and when man-made substances (mainly household 